\title{
Recent results of exenatide use as adjunctive therapy in the treatment of patients with type 2 diabetes
}

This article was published in the following Dove Press journal:

Diabetes, Metabolic Syndrome and Obesity:Targets and Therapy 30 July 2009

Number of times this article has been viewed

\author{
Peggy Soule Odegard' \\ Anthony DeSantis ${ }^{2}$ \\ 'School of Pharmacy, ${ }^{2}$ Division of \\ Metabolism, Endocrinology and \\ Nutrition, Department of Medicine, \\ University of Washington, Seattle, \\ WA, USA
}

\begin{abstract}
Exenatide is a GLP-1 receptor agonist approved for use in type 2 diabetes mellitus. In clinical trials, significant reductions in serum glucose and weight were demonstrated for exenatide with primary glycemic effects of the twice daily formulation on prandial glucose control. In this paper, we review recent research with exenatide as adjunctive therapy in type 2 diabetes mellitus. In particular, studies demonstrate ongoing benefit on glycemic control and weight reduction with continued therapy up to 82 weeks duration and efficacy as adjunctive therapy for patients taking metformin, thiazolidinediones, and/or a sulfonylurea and as compared to sitagliptin and various insulin formulations. Compared to insulin, exenatide likely has greatest benefit for those patients who are overweight or who need improved prandial glucose control. The new long-acting release formulation of exenatide has demonstrated slightly improved efficacy compared to the twice daily formulation as well as a reduction in gastrointestinal side effects. Emerging research is further exploring novel benefits of exenatide as adjunctive DM therapy, effects on prandial glycemic control, markers of hepatic inflammation, alternative dosage forms including intra-nasal administration, and effects on beta cell function.
\end{abstract}

Keywords: exenatide, diabetes, GLP-1

\section{Background}

The prevalence of diabetes mellitus is conservatively estimated at 23 million individuals in the United States. ${ }^{1}$ Weight gain is directly correlated with insulin resistance and predisposes to the development of type 2 diabetes mellitus (T2DM), so it is not surprising that the increasing incidence of this disorder mirrors the epidemic rise in obesity among US citizens. Health care costs related to the treatment of diabetes and its complications are staggering, estimated at US\$116 billion annually. ${ }^{1}$ The development of diabetes associated microvascular complications can be reduced by the improvement in hyperglycemia associated with the condition. ${ }^{2,3}$ Since 1995, therapeutic options for the treatment of T2DM have grown considerably. Unfortunately this increase in pharmacologic choices has not translated into an improvement in individual glycemic targets associated with a reduction in diabetic microvascular complications. ${ }^{4}$ One of the hurdles to improving hyperglycemia is patient adherence to a prescribed medical regimen. Often patients cite a reluctance to gain weight, a common side effect of many available hypoglycemic medications. Therapies that effectively reduce blood glucose and are weight neutral or can promote weight loss are highly sought.

Insulin secretion is more pronounced in response to an oral glucose stimulus compared to a calorically equivalent intravenous glycemic bolus, a phenomenon termed the incretin effect. ${ }^{5}$ This effect, presumed to be the result of a coordinated 
interplay between gut hormones and pancreatic islet cells, can account for up to $70 \%$ of postprandial insulin production. Many intestinal hormones can stimulate insulin secretion, however studies suggest that two gut hormones, glucagon like peptide 1 (GLP-1) and glucose dependent insulinotropic polypeptide (GIP) are predominantly responsible for the incretin effect( 6). Specifically GLP-1 and GIP are secreted following a meal, augment insulin secretion, and their insulinotropic effect is only seen during times of hyperglycemia. Interference with incretin hormone activity is associated with reduced insulin secretion and hyperglycemia., ${ }^{7,8}$ The actions of incretin hormones would suggest an ideal pharmacologic agent for the treatment of hyperglycemia. Despite these factors, administration of GIP to individuals with T2DM has little hyperglycemia ameliorating effect even when given in supraphysiologic doses. ${ }^{9}$ Studies have shown that hyperglycemia down regulates GIP receptors on the beta cell thus reducing the potential for GIP as a therapeutic agent..$^{10}$ In comparison, GLP-1 administration to individuals with T2DM is associated with a response predicted by the administration of an incretin hormone and has been intensely studied as a therapeutic agent in T2DM.

GLP-1 is derived from cleavage of the larger polypeptide, proglucagon, the precursor to related compounds, GLP-2, glucagon, oxyntomodulin and glicentin. ${ }^{11}$ Production and secretion of GLP-1 occurs in the enteroendocrine L-cells of the jejunum and ileum. GLP-1 plasma levels are low in the fasting state but rise significantly in response to meal ingestion. ${ }^{12}$ Certain nutrient types can be more stimulatory, however the exact factors leading to GLP-1 production and secretion are still not known. ${ }^{12,13}$

GLP-1 administration to individuals with and without DM is associated with an augmentation of insulin secretion and activity $^{14}$ as well as a concomitant inhibition of post-meal glucagon production. ${ }^{15}$ This coordinated islet cell hormone production is ideally suited to reduce meal-induced hyperglycemia. Even more salutary is that this function is glucose dependent, predominating only during times of elevated serum glucose, therefore GLP-1 is less likely to induce hypoglycemia. Beyond its glucose regulatory effect, GLP-1 has exhibited CNS appetite control, promoting satiety and decreased GI motility. ${ }^{16}$ Individuals with T2DM or impaired glucose tolerance exhibit reduced GLP-1 serum levels in response to a meal. ${ }^{17,18}$ Moreover GLP-1 secretion post prandially is inversely correlated with the degree of insulin resistance. ${ }^{19}$ In summary, GLP-1 promotes glucose dependent insulin secretion, decreases post-meal glucagon production, inhibits gastric motility, promotes satiety and is deficient in those with
T2DM, making it an ideal pharmacologic agent. Enthusiasm for this concept waned with the realization that GLP-1 is rapidly metabolized following secretion in sera. GLP-1 is inactivated by cleavage at the position 2 alanine residue by the endopeptidase dipeptidyl peptidase 4 (DPP 4). ${ }^{20,21}$ DPP 4 removes two amino acids from the $\mathrm{N}$-terminus residue of GLP-1, a process that inactivates the insulinotropic effect. DPP 4 is secreted from capillary endothelial cells and can quickly and effectively metabolize GLP-1. The half-life of endogenous GLP-1 is 1 to 2 minutes. ${ }^{21}$ Clearly any attempt to utilize these agents pharmacologically would mandate the abrogation of DPP 4 metabolism.

Exendin 4 is a naturally occurring 39 amino acid GLP-1 receptor agonist originally isolated in the saliva of the Gila Monster (Heloderma suspectum). ${ }^{22}$ The peptide has 53\% homology with mammalian GLP-1 with similar incretin hormone physiology. ${ }^{22,23}$ The compound is more resistant to DPP 4 metabolism and therefore has a much longer halflife. Exenatide (Byetta ${ }^{\circledR}$; Amylin Pharmaceuticals, Inc., and Lilly USA, LLC), a synthetic analogue of exendin 4, was approved by the FDA for use in the treatment of T2DM on April 28, 2005. ${ }^{24}$ Exenatide has a half-life of 2 hours when administered subcutaneously. Clinical trials designed to evaluate the glycemic effects of exenatide, either as a solo agent or in combination with other hypoglycemic medications, have proven its efficacy to lower serum glucose and promote weight loss. Exenatide is administered as a $5 \mu \mathrm{g}$ or $10 \mu \mathrm{g}$ dose subcutaneously twice daily.

Among individuals with poorly controlled T2DM on maximal sulfonylurea or metformin therapy, or the combination, exenatide administered in $5 \mu \mathrm{g}$ or $10 \mu \mathrm{g}$ subcutaneous twice daily dosing was associated with a significant hemoglobin $\mathrm{A}_{1 \mathrm{c}}\left(\mathrm{HbA}_{1 \mathrm{c}}\right)$ reduction and weight loss compared to placebo at 30 weeks. ${ }^{25-27}$ Those individuals randomized to receive $10 \mu \mathrm{g}$ twice daily, experienced an average $\mathrm{HbA}_{1 \mathrm{c}}$ reduction of $0.9 \%$ with an associated average weight loss of $1.6 \mathrm{~kg}$. Approximately $40 \%$ of the individuals with a baseline $\mathrm{HbA}_{1 \mathrm{c}}$ of $8.3 \%$ attained $\mathrm{HbA}_{1 \mathrm{c}}$ values $\leq 7 \%$ at study closure. Overall exenatide was well tolerated with the most common side effect being nausea that occurred in a significant minority of individuals but was self limited in the vast majority. Due to the gastrointestinal side effects, it is recommended that exenatide be initiated at a $5 \mu \mathrm{g}$ twice daily dose with titration to $10 \mu \mathrm{g}$ twice daily after one month. In some individuals, gastrointestinal side effects may be limited by administration 10 to 15 minutes prior to a meal. Hypoglycemia was rare in these studies, was most often associated with concomitant sulfonylurea use and abrogated by a decrease in sulfonylurea 
dosing. A summary of the initial clinical trial experience with exenatide can be found in Table 1.

Since the initial release of exenatide, research has continued to explore the long-term effects, efficacy as adjunctive therapy, and to further tease out any pharmacokinetic distinctions in special populations or drug interactions. The following is a summary of the clinical trial research evaluating long-term use and comparative efficacy of exenatide published in the last three years since publication of the initial exenatide trials and its release to the US market.

\section{Methods}

\section{Data sources}

A MEDLINE search (January 2006-April 2009) was conducted with the key words exenatide and Byetta for clinical trials limited to human research published in English. Follow-up searches were performed using key author names. References of identified articles were used for additional citations. BIOSIS Previews and the American Diabetes Association 2008 Scientific Abstracts were used for published abstract information.

\section{Study selection and data extraction}

Clinical trials (prospective, randomized, controlled trials) evaluating the safety and efficacy of exenatide as adjunctive therapy for T2DM in adults and children were selected. Data presented at 2008 diabetes scientific meetings of the American Diabetes Association and the American Association of Clinical Endocrinologists and available in abstract format were included for timeliness and are outlined in the 'Emerging Research' section.

\section{Results}

There were 8 (exenatide) adjunctive therapy clinical trials published between January 1, 2006 and April 30, 2009, including one major report of continuation of the initial three exenatide clinical trials. ${ }^{25-27}$ Three abstracts were published in 2008 presenting clinical trial research.

\section{Clinical trials}

In the last 3 years, exenatide has been evaluated in open label extension trials, as a once weekly formulation, as adjunctive therapy with metformin, sulfonylureas, and/or thiazolidinediones, and as compared to sitagliptin and insulin.

\section{Extension studies}

Several studies ${ }^{28-30}$ have reported the results stemming from an interim (82 week) evaluation of extension of therapy in the three initial multicenter, double-blind, placebo controlled efficacy trials. ${ }^{25-27}$ The most recent report details findings from a 24-month pooled interim analysis of this real world extension of exenatide, highlighting the effects on $\mathrm{HbA}_{1 \mathrm{c}}$, liver function, and weight. ${ }^{31}$ Following completion of the 30-week clinical trials, ${ }^{25-27} 974$ subjects opted to continue open label use of exenatide, however, 453 were excluded due to site closure or late enrollment. Of the 521 remaining subjects considered to be the 2-year eligible intention to treat group, 283 subjects completed the full 2 years of treatment for

Table I Summary of initial exenatide clinical trials

\begin{tabular}{|c|c|c|c|c|c|c|}
\hline \multirow[t]{2}{*}{ Study } & \multicolumn{2}{|c|}{ SFU + exenatide or placebo ${ }^{25}$} & \multicolumn{2}{|c|}{$\begin{array}{l}\text { Met }+ \text { exenatide } \\
\text { or placebo }{ }^{26}\end{array}$} & \multicolumn{2}{|c|}{$\begin{array}{l}\text { Met/SFU + exenatide } \\
\text { or placebo }^{27}\end{array}$} \\
\hline & $\begin{array}{l}\text { Exenatide } \\
10 \mu \mathrm{g} \text { bid }\end{array}$ & Placebo & $\begin{array}{l}\text { Exenatide } \\
10 \mu \mathrm{g} \text { bid }\end{array}$ & Placebo & $\begin{array}{l}\text { Exenatide } \\
10 \mu \mathrm{g} \text { bid }\end{array}$ & Placebo \\
\hline Subjects (N) & 129 & 123 & 113 & 113 & 241 & 247 \\
\hline $\mathrm{HbA}_{\mathrm{Ic}}$ decrease (avg) & $\begin{array}{l}-0.86 \% \\
(P<0.00 I)\end{array}$ & $+0.12 \%$ & $\begin{array}{l}-0.78 \% \\
(P<0.002)\end{array}$ & $+0.08 \%$ & $\begin{array}{l}-0.8 \% \\
(P<0.000 \mathrm{I})\end{array}$ & +0.2 \\
\hline$\leq 7 \% \mathrm{HbA}_{\mathrm{Ic}}(\%)$ & $\begin{array}{l}41 \% \\
(P \leq 0.0002)\end{array}$ & $8.8 \%$ & $\begin{array}{l}46 \% \\
(p<0.01)\end{array}$ & $13 \%$ & $\begin{array}{l}34 \% \\
(P<0.000 I)\end{array}$ & $9 \%$ \\
\hline Wt loss (Avge kg) & $\begin{array}{l}-1.6(P<0.05) \\
\text { baseline } 97 \mathrm{~kg}\end{array}$ & -0.6 & $\begin{array}{l}-2.8 \\
(P<0.001), \\
100 \mathrm{~kg} \\
\text { baseline }\end{array}$ & -0.3 & $\begin{array}{l}-\mathrm{I} .6 \\
(P<0.0 \mathrm{I}) \\
98 \mathrm{~kg} \text { baseline }\end{array}$ & -0.9 \\
\hline Nausea (\%) & $51 \%$ & $7 \%$ & $45 \%$ & $23 \%$ & $49 \%$ & $21 \%$ \\
\hline $\begin{array}{l}\text { Mild to moderate } \\
\text { hypoglycemia }<60 \mathrm{mg} / \mathrm{dL}\end{array}$ & $36 \%$ & $3 \%$ & $5 \%$ & $5 \%$ & $28 \%$ & $13 \%$ \\
\hline Severe hypoglycemia & $0 \%$ & $0 \%$ & $0 \%$ & $0 \%$ & $0 \%$ & $0 \%$ \\
\hline
\end{tabular}

Abbreviations: SFU, sulfonylurea; Met, metformin 
the interim analysis ( 238 withdrew from study due to adverse event $9 \%$, loss of glucose control 3\%, loss to follow-up 5\%, administrative, investigator decision or protocol violation $14 \%$, or withdrawal of consent $15 \%$ ). The initial reduction in $\mathrm{HbA}_{1 \mathrm{c}}(-0.9 \%)$ seen in the pooled analysis of the 3 clinical trials was sustained at 2 years $(-1.1 \%, P<0.001,2$-year completer population) and was significantly lower than baseline. In addition, weight reduction (mean [SD]) was progressive with continuation therapy $(-2.1 \mathrm{~kg}[0.2]$ at 30 weeks to $-4.7 \mathrm{~kg}[0.3]$ at 2 years, $P<0.001$, and BMI reduction of $1.6 \mathrm{~kg} / \mathrm{m}^{2}[0.1], P<0.001$, vs baseline for 2-year completer population). Of note, subjects with slightly elevated ALT at baseline (mean 38 (SEM 1) IU/mL, 53\% of the sample) had a significant mean reduction from baseline (-11 (SEM 1) IU/mL, $P<0.05)$, with 39\% achieving a normal ALT by 104 weeks. These findings support the ongoing use of exenatide for diabetes and weight control, and highlight a potential therapeutic option for those who are overweight with elevated ALT, to improve liver function.

\section{Once weekly formulation}

The use of exenatide may be deferred by some patients taking oral diabetes medications in an effort to avoid the use of injections. Recent research has explored the option of a once weekly formulation of exenatide as a less frequently administered alternate to twice daily injections. In a phase 2 , placebo comparison study, long-acting release (LAR) exenatide $(0.8 \mathrm{mg}$ and $2 \mathrm{mg})$ was studied in adults with T2DM $(\mathrm{N}=45$, baseline $\mathrm{HbA}_{1 \mathrm{c}} 8.3 \%$ to $8.6 \%$ across groups) with or without metformin ( $\mathrm{n}=27$ using metformin). ${ }^{32}$ By week 2, exenatide levels had achieved the desired minimal concentration for effect ( $50 \mathrm{pg} / \mathrm{mL})$. Fasting plasma glucose was significantly reduced at week $15(-43.2 \pm 16.2$ and $-39.6 \pm 9 \mathrm{mg} / \mathrm{dL}$ as computed from $\mathrm{mmol} / \mathrm{L}$ reported for the $0.8 \mathrm{mg}$ and $2 \mathrm{mg}$ groups, respectively, $P<0.001$ vs placebo). The magnitude of postprandial glucose excursion was reduced by a factor of 4 for the $2 \mathrm{mg}$ exenatide LAR group compared to placebo. $\mathrm{HbA}_{1 \mathrm{c}}$ was reduced by $1.4 \%( \pm 0.3)$ and $1.7 \%( \pm 0.3)$ for the $0.8(\mathrm{~N}=16)$ and $2 \mathrm{mg}(\mathrm{N}=15)$ dose groups, respectively, with $36 \%$ of subjects in the $0.8 \mathrm{mg}$ group and $86 \%$ in the $2 \mathrm{mg}$ group achieving $\mathrm{HbA}_{1 \mathrm{c}} \leq 7 \%$ at week 15, compared with $0 \%$ of placebo subjects $(\mathrm{N}=14)$. Additionally, patients in the $2 \mathrm{mg}$ group achieved a $3.8 \mathrm{~kg}$ weight loss $( \pm 1.4 \mathrm{~kg})$ or $3.5 \%$ of baseline body weight at 15 weeks $(P<0.05)$. Body weight was unchanged from baseline for the $0.8 \mathrm{mg}$ and placebo LAR groups. In a study reported by Drucker and colleagues, LAR exenatide 2 mg given subcutaneously (SC) once weekly was compared to $10 \mu \mathrm{g}$ exenatide SC twice daily in an open-label, non-inferiority study in 295 people with T2DM either naïve to treatment or on 1 or more antidiabetic medications. ${ }^{33}$ At 30 weeks, the once weekly exenatide group had a greater reduction in $\mathrm{HbA}_{1 \mathrm{c}}(-1.9 \%$ vs $-1.5 \%$, $P=0.0023)$ and a greater proportion of patients achieved an $\mathrm{HbA}_{1 \mathrm{c}}<7 \%$ (77\% in weekly group vs 61\% in BID group, $P=0.0039)$. Fasting plasma glucose was reduced to a greater extent (-41.4 [SE 3.6] mg/dL vs -25.2 [3.6], $P<0.0001)$, for once weekly and twice daily, respectively. Weight loss was similar for the two treatment groups. Nausea, the most common side effect seen with the twice daily formulation currently available, was reported by $26.4 \%$ of subjects receiving the once weekly formulation as compared to $34.5 \%$ of the twice daily group with vomiting rates of $10.8 \%$ for once weekly and $18.6 \%$ for twice daily administration. Injection site pruritus was reported to a much greater extent (17.6\% vs $1.4 \%$ ) by the group receiving the once weekly formulation. The improved reduction in $\mathrm{HbA}_{1 \mathrm{c}}$ seen with the weekly formulation is likely related to the longer duration of action allowing for ongoing incretin supplementation rather than the shorter, burst supplementation provided by the twice daily formulation which has a half-life of 2 hours resulting in loss of coverage between doses. Patient reported side effects (eg, nausea or bloating) are also less likely with the weekly formulation, possibly related to reduction of daily peak effects. ${ }^{34}$ The use of a once weekly formulation presents a promising new option for those who may benefit from incretin therapy.

\section{Adjunctive therapy comparative trials}

Exenatide has recently been evaluated as adjunctive therapy with metformin, thiazolidinediones, sulfonylureas, or combinations of these and compared with insulin and sitagliptin (Table 2). Overall, the addition of exenatide is beneficial with greatest potential in those who are overweight or with prandial glucose excursions not responding to oral therapy or insulin.

\section{Exenatide vs insulin}

Whether to initiate exenatide or insulin in an individual with uncontrolled T2DM is a decision based on several factors including the need for weight loss, needs for prandial versus basal glucose control, co-morbidities (eg, exenatide contraindication if motility disorders) and patient acceptance of injection therapy. From a pharmacologic standpoint, basal insulin and exenatide therapies are quite different. The usual first step in insulin therapy in T2DM, basal insulin, targets overall control, as measured by fasting plasma glucose, 


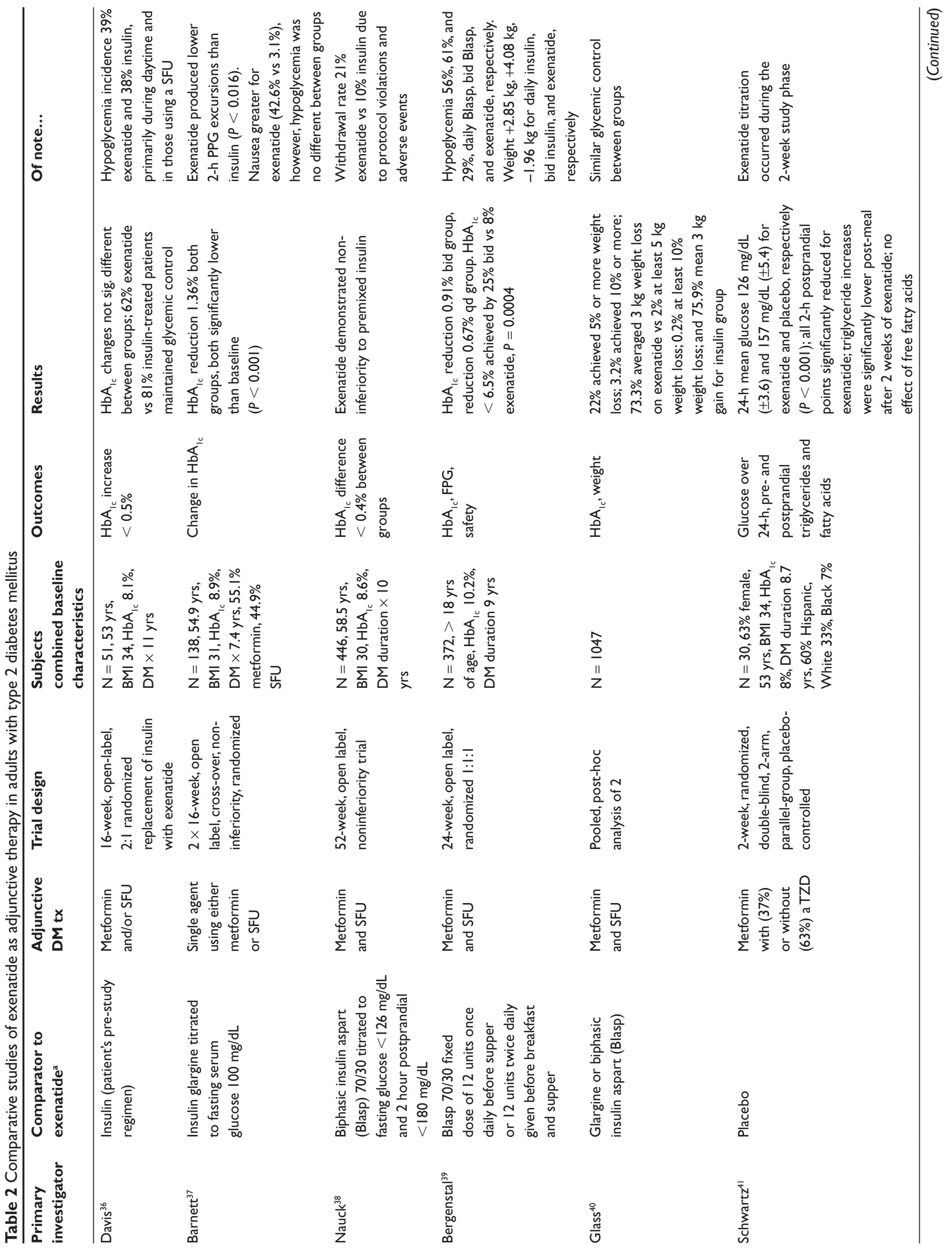




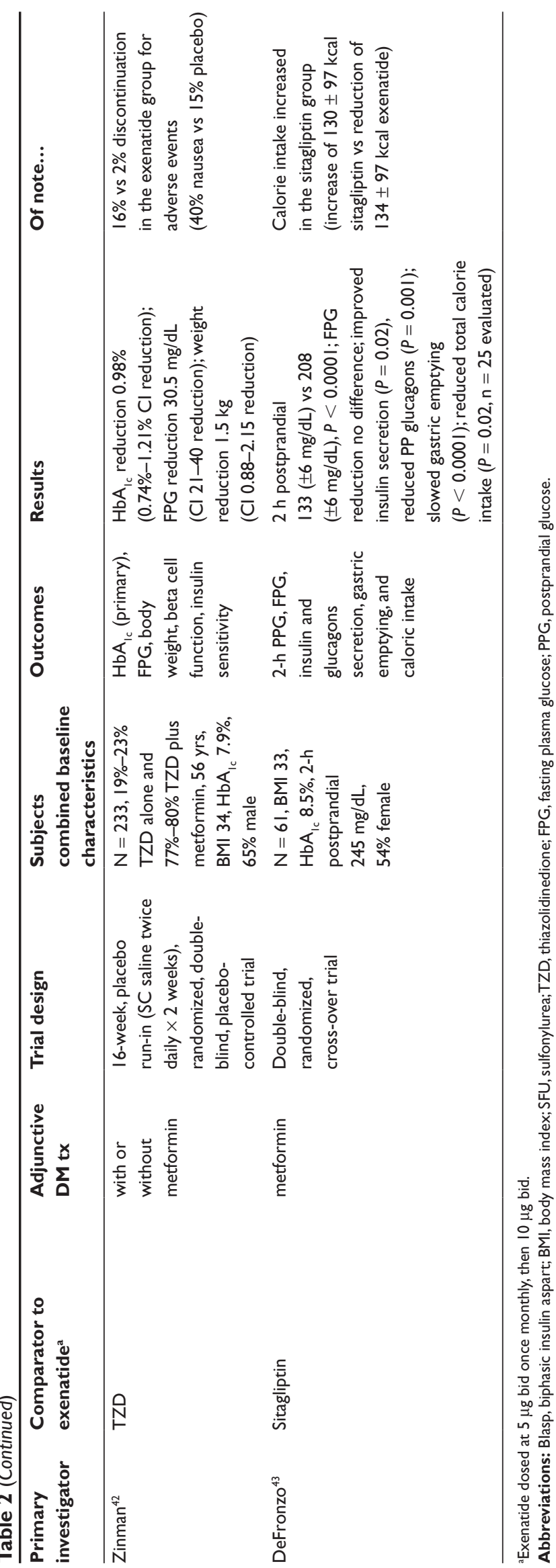

whereas exenatide has a greater impact on reducing prandial glucose excursions. Ideally, decisions about which product to initiate should be made with the specific needs for glucose control in mind. This point is reinforced by an earlier 2005 study comparing the addition of exenatide or insulin glargine in 551 subjects suboptimally controlled on metformin and a sulfonylurea. ${ }^{35}$ In this comparison, no difference in $\mathrm{HbA}_{1 \mathrm{c}}$ reduction (1.11\% both groups) was demonstrated between treatments; however, exenatide had a greater effect on postprandial glucose excursions than insulin glargine, which reduced fasting glucose to a greater extent. In a more recent study, Davis and colleagues investigated the substitution of exenatide for insulin in a 16-week study in adults with T2DM (BMI $>27$ but $<40 \mathrm{~kg} / \mathrm{m}^{2}$ ) using oral antidiabetic agents plus insulin. ${ }^{36}$ In this trial, patients using some level of insulin (NPH, glargine, ultralente, a mix product, or multiple insulin formulations) were included. A 2:1 randomization resulted in 33 subjects switched from their insulin to exenatide ( $5 \mu \mathrm{g} \mathrm{bid} \times$ 4 weeks, then $10 \mu \mathrm{g}$ bid $\times$ next 12 weeks) and 16 subjects continuing their insulin regimen. All subjects continued previous oral antidiabetic medications. In the intention to treat analysis, $62 \%$ of subjects switched to exenatide maintained glycemic control $\left(\mathrm{HbA}_{1 \mathrm{c}}\right.$ increase $\left.<0.5 \%\right)$ as compared to $81 \%$ of the insulin treated group. Subjects in the exenatide group $(n=18)$ who had the greatest improvement were those using less insulin, having shorter diabetes duration, higher c-peptide levels, and on insulin for shorter duration. Of the 11 exenatide-treated subjects who did not maintain glycemic control, 5 discontinued exenatide prior to completing the study period, primarily due to loss of glucose control. Overall, the differences in glycemic control between the two groups were not statistically significant. Gastrointestinal adverse events were reported in higher frequency for the exenatide. In particular, $79 \%$ of exenatide subjects reported a treatmentemergent adverse event ( $48.5 \%$ nausea) compared to $56 \%$ of the insulin group ( $31.3 \%$ headache, $12.5 \%$ nausea). Incidence of hypoglycemia was similar between groups (39\% exenatide and $38 \%$ insulin), primarily occurring during the daytime and in those using a sulfonylurea. Although this study suggests the possibility of replacing insulin with exenatide, it is difficult to fully assess the benefit of this approach given the high drop-out rate in the exenatide group. In addition, the inclusion of all insulin use in this study clouds the ability to discern the true benefit of substitution therapy given that the action of twice daily exenatide, the formulation used in the study, is directed more at prandial control than basal.

In an open-label crossover study comparing exenatide to titrated glargine in 138 adults with previously uncontrolled 
diabetes on metformin $(55.1 \%)$ or a sulfonylurea $(44.9 \%)$, Barnett and colleagues found that both exenatide and glargine were associated with similar reductions in $\mathrm{HbA}_{1 \mathrm{c}}(-1.36 \%$ each medication, $P<0.001)$ with no significant difference in the proportion of patients achieving the American Diabetes Association (ADA) target $\mathrm{HbA}_{1 \mathrm{c}}<7 \%$. $^{37}$

In a multi-country randomized trial, biphasic insulin aspart (ie premixed insulin, 70/30) twice daily was compared to twice daily exenatide in a 52-week non-inferiority study ( $n=501$, intention to treat) in overweight or obese patients (BMI baseline $30.4 \mathrm{~kg} / \mathrm{m}^{2}$ ) suboptimally controlled $\left(\mathrm{HbA}_{1 \mathrm{c}}\right.$ greater than or equal to $7 \%$ but less than or equal to $11 \%$ ) on metformin and a sulfonylurea. ${ }^{38}$ Following randomization, subjects in the exenatide group were titrated to $10 \mu \mathrm{g}$ twice daily exenatide over 1 month. Premixed insulin aspart was initiated for the comparator group by investigators and then titrated on an as needed basis to achieve optimal glycemic control, however, a forced titration was not used to guide dosing. Results demonstrated non-inferiority of the exenatide to premixed insulin $\left(\mathrm{HbA}_{1 \mathrm{c}}-1.04 \% \pm 0.07 \%\right.$ exenatide and $-0.89 \% \pm 0.06 \%$ biphasic insulin aspart, $P=0.067$ ). A secondary finding was a significant reduction in weight with mean change from baseline of $-2.5 \mathrm{~kg}$ and $+2.9 \mathrm{~kg}$ for exenatide and premixed insulin, respectively, resulting in a between group difference at week $52(-5.4 \mathrm{~kg}, P<0.001)$.

A second comparison of exenatide to $70 / 30$ biphasic insulin aspart was recently published by Bergenstal et al. ${ }^{39}$ In this study, adult subjects taking metformin and a sulfonylurea with $\mathrm{HbA}_{1 \mathrm{c}}>8 \%$ were randomized to either once or twice daily biphasic aspart or exenatide $(1: 1: 1, \mathrm{~N}=372)$. Glycemic control was significantly improved in the two groups using biphasic aspart as compared to those receiving exenatide $\left(\mathrm{HbA}_{1 \mathrm{c}}\right.$ difference of $-0.91 \%, \mathrm{CI}-1.23 \%$ to $-0.59 \%$ for biphasic aspart twice daily; $-0.67 \%$ reduction, $\mathrm{CI}-0.99 \%$ to $-0.34 \%$ biphasic aspart once daily) although hypoglycemia was less frequent for the exenatide study group (56\%, 61\%, $29 \%$ for biphasic aspart once daily, twice daily, and exenatide, respectively). Weight gain of 2.85 to $4.08 \mathrm{~kg}$ occurred in the insulin groups with an average weight loss of $1.96 \mathrm{~kg}$ in the exenatide group. Of note, the baseline $\mathrm{HbA}_{1 \mathrm{c}}$ was $10.2 \%$ in this trial with mean duration of diabetes of almost 9 years, indicating the potential for greater need or benefit from insulin over exenatide therapy for these subjects.

In addition to effects on $\mathrm{HbA}_{1 \mathrm{c}}$, weight change has been evaluated in insulin comparative trials. In a pooled post-hoc analysis of two multicenter, randomized, open-label trials $(\mathrm{N}=1047$ ) comparing exenatide to insulin (glargine or biphasic insulin aspart) in individuals using metformin and a sulfonylurea, weight loss (a secondary outcome of these trials) was achieved in the exenatide group (73\% averaging $3 \mathrm{~kg}$ loss, 22\% achieving 5\% or more weight loss) as compared to the insulin group in which $76 \%$ of subjects gained weight (mean $3 \mathrm{~kg}$ ) with only $2 \%$ achieving $5 \%$ or more weight loss. ${ }^{40}$ This study highlights the potential benefit of weight loss in exenatide users, however, strict interpretation is difficult given the post-hoc design.

\section{Exenatide vs oral DM therapies}

In patients using oral antihyperglycemic therapies for T2DM, exenatide is an adjunctive therapy option to add to pre-existing metformin therapy with or without a sulfonylurea. Recently, exenatide has been studied as adjunctive therapy to metformin with or without a thiazolidinedione (TZD), TZD monotherapy, and compared with sitagliptin, a DPP-4 inhibitor. A 2-week study of exenatide titrated to $10 \mu \mathrm{g}$ twice daily in adults $(\mathrm{N}=17)$ vs placebo $(\mathrm{N}=13)$, added to metformin $(63 \%)$ or metformin plus a thiazolidinedione (37\%) further explored exenatide as adjunctive therapy. ${ }^{41}$ After the 2-week treatment period, 24-hour glucoses averaged $126 \mathrm{mg} / \mathrm{dL}( \pm 3.6)$ and $157 \mathrm{mg} / \mathrm{dL}( \pm 5.4)$ in the exenatide and placebo groups, respectively. Significant differences $(P \leq 0.001)$ between groups were noted for 2-hour postprandial values at all meal times (119 vs 216, 158 vs 213, and 122 vs 204 mg/dL), with triglyceride excursions significantly reduced after morning and evening meals for the exenatide group. This study highlights the impact on postprandial glucose of this therapy when used as an adjunct. In a randomized, placebo-controlled evaluation of exenatide adjunctive therapy with thiazolidinedione (TZD) treatment for 16 weeks in 233 subjects (ages 21 to 75 years, stabilized on TZD for at least 4 months) from Canada, Spain, and the United States using either metformin or no other therapy, $\mathrm{HbA}_{1 \mathrm{c}}$ was reduced by an additional $0.98 \%$ (95\% CI $-1.21 \%$ to $-0.74 \%){ }^{42}$ In addition to $\mathrm{HbA}_{1 \mathrm{c}}$ reduction with adjunctive therapy, weight reduction of a mean of $1.75 \mathrm{~kg}$ (CI -2.15 to $-0.88 \mathrm{~kg}$ ) or $1.8 \%$ reduction occurred in the exenatide group. Of note, $16 \%$ of the subjects in the exenatide group discontinued treatment as compared to $2 \%$ in the placebo group due to adverse events, primarily due to nausea ( $40 \%$ exenatide vs $15 \%$ placebo). In a 2 -week crossover trial, exenatide was compared to sitagliptin as adjunctive therapy to metformin with significantly improved exenatide efficacy on all measures including postprandial glucose lowering (mean $133 \pm 6$ exenatide vs $208 \pm 6$ sitagliptin $\mathrm{mg} / \mathrm{dL}$, $P<0.00001$ ), increased insulin secretion, reduced postprandial glucagon secretion, reduced postprandial triglycerides, 
slower gastric emptying, and reduced calorie intake. ${ }^{43}$ Given the more targeted action of exenatide at mimicking glucagonlike peptide(GLP-1) compared with sitagliptin which impairs breakdown of GLP-1, these results are to be expected.

\section{Beta cell function}

Research on exenatide suggests a beneficial effect on first and second phase insulin secretion. ${ }^{44}$ Two recent studies have explored this potential using measurement and simulation of beta cell function. These studies have been included in this update to provide evidence on the potential benefit of exenatide on beta cell function when used as adjunctive therapy.

In a 52-week study evaluating the effect on beta cell function of the addition of exenatide or insulin glargine to ongoing metformin therapy, change in blood glucose and C-peptide secretion in 60 subjects was measured prior to, at 52-weeks, and after a 4 -week off-treatment period. ${ }^{45}$ Baseline $\mathrm{HbA}_{1 \mathrm{c}}$ ranged from 7.6\% $( \pm 0.1)$ for the exenatide group to $7.4 \%( \pm 0.1)$ for the glargine group. Although $\mathrm{HbA}_{1 \mathrm{c}}$ reductions were similar for exenatide and glargine groups $(-0.8 \% \pm 0.1 \%$ and $-0.7 \% \pm 0.2 \%$, respectively, at 52 weeks, $P=0.55$ ), parameters of beta cell function were improved in the exenatide group significantly as compared to the glargine group. In particular, first and second phase C-peptide secretion were increased $1.53( \pm 0.11)$ and $2.85 \pm 0.22$ fold, respectively $(P<0.00001)$. Of note, measures of beta cell function returned to pre-treatment levels by 4 weeks after treatment discontinuation, implying a benefit only while drug is present.

A second evaluation used mathematical modeling from data in an exenatide adjunctive therapy investigation to examine the effect of exenatide on predicted insulin secretion and beta cell function in adults with T2DM treated with metformin or metformin and a sulfonylurea. ${ }^{46}$ Using data from mealtime blood glucose tests at baseline and week 30 for the model, an increase in insulin secretion was predicted for exenatide $10 \mu \mathrm{g}$ (72\% predicted increase, $P=0.015)$ and a slightly less profound increase predicted for $5 \mathrm{mcg}$ doses (40\% predicted increase, $P=0.045$ ). These authors suggest the effect of exenatide on improved beta-cell function in their concluding remarks; however, it is difficult to draw specific conclusions given the theoretical nature of the model. This early work suggests a novel benefit of exenatide in those with T2DM not yet seen with other DM medications; however, further research to tease out the specific influence of exenatide on beta cell function and potential recovery is needed.

\section{Emerging research}

At the 2008 meetings of the ADA and AACE, new research yet unpublished but available in abstract form highlighted novel dosage forms of exenatide (intranasal), ${ }^{47}$ positive effects of exenatide on post-meal metabolism and lipid response, ${ }^{48}$ and a beneficial influence of exenatide treatment on liver enzymes. ${ }^{49}$

\section{Summary}

Exenatide is a GLP-1 agonist administered as a $5 \mu \mathrm{g}$ or $10 \mu \mathrm{g}$ dose subcutaneously twice daily which promotes satiety, post-meal glucagon suppression, and insulin release in response to meals. Collectively, these actions result in improved post-meal hyperglycemia, overall $\mathrm{HbA}_{1 \mathrm{c}}$ control, and some degree of weight loss. In clinical trials of adults with T2DM, significant reductions in serum glucose and weight have been demonstrated for exenatide with primary glycemic effects of the twice daily formulation on prandial glucose control. Based on clinical trials, efficacy of exenatide appears more optimal in those who have not had long diabetes duration and those who have adequate endogenous insulin. Recent research with exenatide demonstrates ongoing benefit on glycemic control and weight reduction with continued therapy up to 82 weeks' duration. Additionally, studies have demonstrated efficacy of exenatide as adjunctive therapy for patients taking metformin, thiazolidinediones, and/or a sulfonylurea. As compared to sitagliptin, exenatide has superior efficacy. Compared with insulin, exenatide likely has greatest benefit for those patients who are overweight or who need improved prandial glucose control; however additional study is warranted to fully distinguish the role of exenatide versus insulin. The new long-acting release formulation of exenatide has demonstrated slightly improved efficacy compared with the twice daily formulation as well as a reduction in gastrointestinal side effects. The influence of exenatide on beta cell recovery requires further investigation; however, the initial studies demonstrate improved insulin secretion in the presence of exenatide. Emerging research is further exploring novel benefits of exenatide as adjunctive T2DM therapy including effects on prandial glycemic control and markers of hepatic inflammation. Additionally, alternative dosage forms including intra-nasal exenatide are under investigation.

\section{Conclusion}

Exenatide is an effective option as adjunctive therapy for T2DM in those taking metformin, sulfonylureas, thiazolidinediones, or insulin. The benefit appears greatest for 
individuals with inadequate prandial glycemic control or for whom weight reduction is desired. The use of exenatide has been limited by gastrointestinal side effects, cost, and the need for twice daily subcutaneous injection. Gastrointestinal side effects and the need for frequent injections may be abated somewhat with use of the long-acting release, once weekly formulation if it becomes available. Further research on the potential effects of exenatide on beta cell proliferation is needed to distinguish the benefits of therapy on insulin secretion, which has been demonstrated, versus insulin production or beta cell recovery.

\section{Disclosure}

The authors declare no conflicts of interest.

\section{References}

1. CDC fact sheet. http://www.cdc.gov/diabetes/pubs/factsheet07.htm. Accessed April 2, 2009.

2. The Diabetes Control and Complications Research Group. The effect of intensive diabetes treatment on the development and progression of long term complications in insulin dependent diabetes mellitus. $N$ Engl J Med. 1993;329:977-986.

3. UK Prospective Diabetes Study Group. Intensive blood-glucose control with sulphonylureas or insulin compared to conventional treatment and risk of complications in subjects with type 2 diabetes mellitus. (UKPDS 33) Lancet. 1998;352:837-853.

4. Koro CE. Bowlin SJ, Bourgeois N, Fedder DO. Glycemic control from 1988 to 2000 among US adults diagnosed with type 2 diabetes: A preliminary report Diabetes Care. 2004;27:17-20.

5. Elrick H, Stimmler L, Hlad CJ, Arai Y. Plasma insulin responses to oral and intravenous glucose administration. J Clin Endocrinol Metab. 1964;24:1076-1082.

6. Drucker D. Enhancing incretin action for the treatment of type 2 diabetes. Diab Care. 2003;26:2929-2940.

7. Elahi D, McAloon-Dyke M, Fukagawa NK, Meneilly GS, Sclater AL, Minaker KL, et al. The insulinotropic actions of glucose-dependent insulinotropic polypeptide (GIP) and glucagon-like polypeptide 1 (7-37) in normal and diabetic subjects. Regul Pept. 1994;51:63-74.

8. Tseng CC, Zhang XY, Wolfe MM. Effect of GIP and GLP-11 antagonists on insulin release in the rat. Am J Physiol. 1999;276: E1049-E1054.

9. Jones IR, Owens DR, Vora J, Luzio SD, Hayes TM. A supplementary infusion of glucose - dependent insulinotrpic olypeptide (GIP) with a meal does not significantly improve the beta cell response or glucose tolerance in type 2 diabetes mellitus. Diabetes Res Clin Pract. 1989;7:263-269.

10. Tseng CC, Boylan MO, Jarboe LA, Usdin TB, Wolfe MM. Chronic desensitization of the glucose-dependent insulinotropic polypeptide receptor in rats. Am J Physiol. 1996;270:E661-E666.

11. Bell GI, Sanchez-Pescador R, Laybourn PJ, Najarian RC. Exon duplication and divergence in the human preproglucagon gene. Nature. 1983;304:368-371.

12. Hermann C, Goke R, Richter G, Fehmann HC, Arnold R, Goke B. Glucagon-like peptide 1 and glucose dependent insulin releasing polypeptide plasma levels in response to nutrients. Digestion. 1995;56: $117-126$

13. Elliot RM, Morgan LM, Tredger JA, Deacon S, Wright J Marks V. Glucagon-like peptide 1 (7-36) amide and glucose dependent insulinotropic polypeptide secretion in response to nutrient ingestion in man: acute post-prandial and 24 hour secretion patterns. J Endocrinol. 1993;138:159-166.
14. Vahl TP, Paty BW, Fuller BD, Prigeon RL, D'Alessio DA. Effects of GLP-1-1- (7-36)NH(2), GLP-1-1-(7-37), and GLP-1-1-(9-36)NH(2) on intravenous glucose tolerance and glucose-induced insulin secretion in healthy humans. J Clin Endocrinol Metab. 2003;88:1772-1779.

15. Matsuyama T, Komatsu R, Namba M, Watanabe N, Itoh H, Tarui S. Glucagon-like peptide 1 (7-36 amide): a potent glucagonostatic and insulinotropic hormone. Diabetes Res Cln Pract. 1988;5:281-284.

16. Turton MD, O'Shea D, Gunn I, Beak SA, Edwards CMB, Meeran K, et al. A role for glucagon-like peptide-1 in the central regulation of feeding. Nature. 1996;379:69-72.

17. Lugari R, Dei CA, Ugolotti D, Finardi L, Barilli A, Ognibene C, et al. Evidence for early impairment of glucagon-like peptide 1 induced insulin secretion in human type 2 (non-insulin dependent) diabetes Horm Metab Res. 2002;34:150-154.

18. Vilsboll T, Krarup T, Deacon CF, Madsbad S, Holst JJ. Reduced postprandial concentrations of intact biologically active glucagon-like peptide 1 in type 2 diabetic patients. Diabetes. 2001;50:609-613.

19. Rask E, Olsson T, Soderberg S, et al. Impaired incretin response after a mixed meal is associated with insulin resistance in non-diabetic men. Diabetes Care. 2001;24:1640-1645.

20. Mentlein R, Gallwitz B, Schmidt WE. Dipeptidyl-peptidase 4 hydrolyses gastric inhibitory polypeptide, glucagon-like peptide-1 (7-36) amide, peptide histidine methionine and is responsible for their degradation in human serum. Eur J Biochem. 1993;214:829-835.

21. Vilsboll T, Agerso H Krarup T Holst JJ. Similar elimination rates of glucagon-like peptide- 1 in obese type 2 diabetic patients and healthy subjects. J Clin Endocrinol Metab. 2003;88:220-224.

22. Eng J, Kleinman WA, Singh L, Singh G, Raufman JP. Isolation and characterization of exendin 4, an exendin 3 analogue from Heloderma suspectum venom. J Biol Chem. 1992;267;7402-7405.

23. Chen YE, Drucker DJ. Tissue-specific expression of unique mRNAs that encode proglucagon-derived peptides or exendin 4 in the lizard. J Biol Chem. 1997;272:4108-4115.

24. Center for Drug Evaluation and CDER Drug and Biologic Approvals for Calendar Year 2005. www.fda.gov/cder/rdmt/InternetNDA05.htm. Accessed April 14, April 14, 2009.

25. Buse JB, Henry RR, Han J, Kim DD, Fineman MS, Barron AD: the Exenatide-113 Clinical Study Group. Effects of exenatide (exendin-4) on glycemic control over 30 weeks in sulfonylurea-treated patients with type 2 diabetes. Diabetes Care. 2004;27:2628-2635.

26. DeFronzo RA, Ratner RE, Han J, Kim DD, Fineman MS, Barron AD. Effects of exenatide (exendin-4) on glycemic control and weight over 30 weeks in metformin-treated patient with type 2 diabetes. Diabetes Care. 2005;28:1092-1100.

27. Kendall DM, Riddle MC, Rosenstock J, Zhuang D, Kim DD, Fineman MS, et al. Effects of exenatide (exendin-4) on glycemic control over 30 weeks in patients with type 2 diabetes treated with metformin and a sulfonylurea. Diabetes Care. 2005;28:1083-1092.

28. Ratner RE, Maggs D, Nielsen LL, Stonehouse AH, Poon T, Zhang B, et al. Long-term effects of exenatide therapy over 82 weeks on glycaemic control and weight in over-weight metformin-treated patients with type 2 diabetes mellitus. Diabetes Obes Metab. 2006;8:419-428.

29. Blonde L, Klein EJ, Han J, Zhang B, Mac SM, Poon TH, et al. Interim analysis of the effects of exenatide treatment on $\mathrm{A} 1 \mathrm{C}$, weight, and cardiovascular risk factors over 82 weeks in 314 overweight patients with type 2 diabetes. Diabetes Obes Metab. 2006:8:436-447.

30. Riddle MC, Henry RR, Poon TH, Zhang B, Mac SM, Holcombe JH, et al. Exenatide elicts sustained glycaemic control and progressive reduction of body weight in patients with type 2 diabetes inadequately controlled by sulphonulureas with or without metformin. Diabetes Metab Res Rev. 2006;22:483-491.

31. Buse JB, Klonoff DC, Nielsen LL, Guan X, Bowlus CL, Holcombe JH, et al. Metabolic effects of two years of exenatide treatment on diabetes, obesity, and hepatic biomarkers in patients with type 2 diabetes: An interim analysis of data from the open-label, uncontrolled extension of three double-blind, placebo-controlled trials. Clinical Therap. 2007;29:139-153. 
32. Kim D, MacConell L, Zhuang D, Kothare PA, Trautmann M, Fineman M, et al. Effects of once-weekly dosing of a long-acting release formulation of exenatide on glucose control and body weight in subjects with type 2 diabetes. Diabetes Care. 2007;30:1487-1493.

33. Drucker DJ, Buse JB, Taylor K, Kendall DM, Trautmann M, Zhuang D, et al; DURATION-1 Study Group. Exenatide once weekly versus twice daily for the treatment of type 2 diabetes: a randomized, open-label, non-inferiority study. Lancet. 2008;372:1240-1250.

34. Richardson, K. Medscape diabetes and endocrinology. incretin-based therapies in type 2 diabetes: An expert interview with John B. Buse, MD, PhD, CDE. 2008:8(1). http://www.medscape.com/viewarticle/537094 Accessed March 6, 2009.

35. Heine RJ, Van Gaal LF, Johns D, Mihm MJ, Widel MH, Brodows RG; GWAA Study Group. Exenatide versus insulin glargine in patients with suboptimally controlled type 2 diabetes: a randomized trial. Ann Intern Med. 2005;143:559-569.

36. Davis SN, Johns D, Maggs D, Xu H, Northrup JH, Brodows RG. Exploring the substitution of exenatide for insulin in patient with type 2 diabetes treated with insulin in combination with oral antidiabetes agents. Diabetes Care. 2007;30:2767-2772.

37. Barnett AH, Burger J, Johns D, Brodows R, Kendall DM, Roberts A, et al. Tolerability and efficacy of exenatide and titrated insulin glargine in adult patients with type 2 diabetes previously uncontrolled with metformin or a sulfonylurea: a multinational, randomized, openlabel, two-period, cross-over noninferiority trial. Clin Ther. 2007;29: 2333-2348.

38. Nauck MA, Duran S, Kim D, Johns D, Northrup J, Festa A, et al. A comparison of twice-daily exenatide and biphasic insulin aspart in patients with type 2 diabetes who were suboptimally controlled with sulfonylurea and meformin: a non-inferiority study. Diabetologia. 2007;50:259-267.

39. Bergenstal R, Lewin A, Bailey T, Chang D, Bylvin T, Roberts; NovoLog Mix vs Exenatide Study Group. Efficacy and safety of biphasic insulin aspart 70/30 versus exenatide in subjects with type 2 diabetes failing to achieve glycemic control with metformin and a sulfonylurea. Curr Med Res Opin. 2009;25:65-75.

40. Glass LD, QU Y, Lenox S, Kim D, Gates JR, Brodows R, et al. Effects of exenatide versus insulin analogues on weight change in subjects with type 2 diabetes: a pooled post-hoc analysis. Curr Med Res Opin. 2008;24:639-644.
41. Schwartz SL, Ratner RE, Kim DD, Qu Y, Fechner LL, Lenox SM, et al. Effect of exenatide on 24-hour blood glucose profile compared with placebo in patients with type 2 diabetes: a randomized, double-blind, two-arm, parallel-group, placebo-controlled, 2-week study. Clin Ther. 2008;30:858-867.

42. Zinman B, Hoogwerf BJ, Duran Garcia S, Milton DR, Giaconia JM, Kim DD, et al. The effect of adding exenatide to a thiazolidinedione in suboptimally controlled type 2 diabetes: a randomized trial. Ann Intern Med. 2007; 146:477-485.

43. DeFronzo RA, Okerson T, Viswanathan P, Guan X, Holcombe JH, MacConell L. Effects of exenatide versus sitagliptin on postprandial glucose, insulin and glucagons secretion, gastric emptying, and caloric intake: a randomized, cross-over study. Curr Med Res Opin. 2008;24:2943-2952.

44. Fehse F, Trautmann M, Holst JJ, Halseth AE, Nanayakkara N, Nielsen LL, et al. Exenatide augments first- and second-phase insulin secretion in response to intravenous glucose in subjects with type 2 diabetes. J Clin Endo Metab. 2005;29:2333-2348.

45. Bunck MC, Diamant M, Corner A, Eliasson B, Malloy JL, Shaginian RM, et al. One-year treatment with exenatide improves beta-cell function, compared to insulin glargine, in metformin treated type 2 diabetes patients: A randomized, controlled trial. Diab Care. 2009. [Epub ahead of print] PMID 19196887.

46. Mari A, Nielsen LL, Nanayakkara N, DeFronzo RA, Ferrannini E, Halseth A. Mathematical modeling shows exenatide improved betacell function in patients with type 2 diabetes treated with metformin or metformin and a sulfonylurea. Horm Metab Res. 2006;38:838-844.

47. Blasé E, Deng W, Walsh B, Fineman M, Rhodes C. Intranasal administration of exenatide in patients with type 2 diabetes: pharmacokinetics, pharmacodynamics, safety, and tolerability. American Diabetes Association, 68th Scientific Sessions. 2008; abstract 195-OR.

48. Bunck MC, Corner A, Diamant M, Eliasson B, Malloy JL, Shaginian RM, et al. Exenatide improves postprandial hyperglycemia and dyslipidemia in metformin treated patients with type 2 diabetes. American Diabetes Association. 68th Scientific Sessions. 2008; abstract 109-OR.

49. Bulchandani K, Nachnani JS, Eaton C, Hamburg M. Exenatide leads to reduction in liver enzymes in diabetics independent of weight loss. American Association of Clinical Endocrinologists. Annual Meeting. 2008; abstract 240 .

\section{Publish your work in this journal}

Diabetes, Metabolic Syndrome and Obesity: Targets and Therapy is an international, peer-reviewed open-access journal committed to the rapid publication of the latest laboratory and clinical findings in the fields of diabetes, metabolic syndrome and obesity research. Original research, review, case reports, hypothesis formation, expert opinion and commentaries are all considered for publication. The manuscript management system is completely online and includes a very quick and fair peer-review system, which is all easy to use. Visit http://www.dovepress.com/testimonials.php to read real quotes from published authors. 